\title{
O manguebeat e a superação do fosso entre o nacional e o jovem na música popular
}

\author{
Idelber Avelar ${ }^{1}$
}

\begin{abstract}
Resumo
Este artigo analisa o movimento musical e cultural Mangue Beat a partir de uma de suas marcas registradas, o diálogo entre gêneros estrangeiros marginais ao panteão do pop rock internacional (heavy metal, hip hop, raggamuffin) e gêneros brasileiros tidos como regionais e não canonizados no panteão da música nacional (coco, maracatu, ciranda, embolada). O emblema do movimento, a parabólica fincada na lama, combina as raízes na realidade local com a atenção permanente aos fluxos globais. A tese do artigo é que o Mangue Beat supera o fosso entre música popular e música jovem aberto a partir da crise do potencial contestatário e emancipatório da MPB no período de transição à democracia.
\end{abstract}

Palavras-chave: manguebeat, globalização, hibridismo, MPB, cânone musical.

\begin{abstract}
This article analyzes the cultural and musical movement known as Mangue Beat, focusing on one of its trademarks, namely the dialogue between international genres marginal to the pop and rock music canon (heavy metal, hip hop, reggamuffin) and Brazilian genres seen as regional and not canonized in the pantheon of national music (coco, maracatu, ciranda, embolada). The movement's emblem, the antenna stuck in the mud, combines local roots with permanent attention to global flows. The article argues that Mangue Beat
\end{abstract}

${ }^{1}$ Tulane University. 
overcomes the rift between popular music and youth music in Brazil, opened with the crisis in the emancipatory potential of MPB in the period of transition to democracy.

Keywords: manguebeat, globalization, hybridity, MPB, musical canon.

Em meados de 91 começon a ser gerado e articulado em vários pontos da cidade um núcleo de pesquisa e produção de ideias pop. O objetivo é engendrar um "circuito energético", capaz de conectar as boas vibraçoes dos mangues com a rede mundial de circulação de conceitos pop. Imagem símbolo, uma antena parabólica enfiada na lama.

Os mangueboys e manguegirls são indivíduos interessados em: quadrinhos, TV interativa, anti-psiquiatra, Bezerra da Silva, Hip Hop, midiotia, artismo, música de rua, John Coltrane, acaso, sexo não-virtual, conflitos étnicos e todos os avanços da química aplicada no terreno da alteração e expansão da consciência.

(Manifesto manguebeat, Recife, 1994)

Nova York, junho de 1995: um amigo me conta que o show de verão SummerStage, no Central Park, estrelado por Gilberto Gil, vai ser aberto por um vocalista de nome interessante, Chico Science, com uma banda de nome ainda mais sugestivo, Nação Zumbi (daqui em diante, CSNZ). Naquela época eles eram razoavelmente conhecidos no Brasil, já com um disco de estreia, $D a$ lama ao caos, lançado com sucesso em 1994. Nos primórdios da Internet, no entanto, um expatriado tinha que labutar para se manter atualizado com a safra da música nacional. O fato é que estávamos em meados de $1995 \mathrm{e} \mathrm{eu} \mathrm{ainda} \mathrm{não}$ tinha ouvido falar de Chico Science ou do manguebeat. Que eu tenha considerado a possibilidade de nem mesmo aparecer no show de abertura e chegar direto para o de Gil no fim da tarde é um testemunho da segmentação, do fosso entre a música do Nordeste e os gostos de ouvintes de classe média do Sudeste como eu. Acabei chegando para ver o show de CSNZ, que me deixou boquiaberto como poucos espetáculos jamais haviam deixado. A primeira coisa que chamava a atenção era a mescla de coisas que nunca haviam sido justapostas antes. Isso não era e não é, para mim, um valor em si mas, naquele caso, com certeza funcionava: a mistura era insólita e contagiante, polissêmica e ao mesmo tempo concisa.

À frente de uma banda que unia os tambores do maracatu com a formação clássica do rock (guitarra / baixo / bateria), Chico Science realizava uma performance vocal que emprestava tanto da ciranda como da embolada e do hip hop. A combinação entre tambores e o trio de instrumentos do rock já havia sido usada por Lenine, em Baque Solto, gravado em 1983 com Lula 
Quiroga $^{2}$, mas é Chico Science quem consolida e extrai as consequências do diálogo entre a batida poderosa do maracatu, ritmo de energia e precisão, e a formação guitarra / baixo / bateria: "um melhor posicionamento dos microfones e amplificação de cada alfaia individual, técnicas que ele [Science] viu em concertos de maracatu da Nação Pernambuco, no começo dos anos 90, aumentaram o controle dos músicos sobre o tom da seção rítmica, adicionando assim um importante ingrediente ao som de CSNZ" ". O som de CSNZ não era uma fusão: preservava-se a intensidade de cada gênero canibalizado, sem que eles se diluíssem. Havia sempre mais de um ritmo acontecendo ao mesmo tempo, mas eles nunca convergiam rumo a uma síntese. As referências aos diferentes gêneros se sucediam umas às outras em velocidade frenética, justapostas de maneiras inesperadas.

CSNZ sistematicamente transgredia fronteiras: da música de capoeira sobre um groove de funk a uma guitarra samba-rock sobre uma batida de maracatu, logo depois reduzida a um andamento de reggae pontuado por efeitos eletrônicos, sampling ou scratching, não raro superpostos a guitarras distorcidas com pedais wah wah, em estilo heavy metal. As letras eram radicais, surreais, ultrajantes, tecnófilas. Canibalizavam um vasto repertório e indicavam uma abordagem da globalização dos fluxos culturais que dialogava não apenas com a grande tradição das letras da música brasileira, mas também com tendências globais como o ciberpunk: "as roupas da banda, como por exemplo o uso de óculos Rayban e chapéus de palha dos pescadores pernambucanos, também incorporavam sua identidade transcultural" ${ }^{4}$. CSNZ cruzava tantas fronteiras culturais e musicais que um recém chegado à sua música não saberia como classificá-los: era uma banda pop ou um grupo folclórico? Como era possível que canibalizasse tantos gêneros anglo-americanos e afro-atlânticos e ainda mantivesse referências regionais tão claras? Que tipo de combinação insólita era aquela? Quem seriam os ouvintes com suficiente bagagem cultural para saber de onde vinha o som de CSNZ?

Seria difícil descrever a impressão que me causou aquela hora de estrondo musical de CSNZ no Central Park. Havia algo de lírico, mas a música era incrivelmente alta e poderosa; sua apropriação de ícones culturais familiares era irônica, mas ao mesmo tempo respeitosa e instigante. Quando Gilberto Gil subiu ao palco para acompanhá-los, eu tive a sensação de, pela primeira vez em anos, estar vendo um grupo de música brasileira capaz de estabelecer um diálogo com a tradição sem ansiedade ou reverência. Até hoje, considero aquela apresentação de CSNZ no New York SummerStage a mais impressionante de uma banda brasileira que já vi. Imediatamente comprei o CD Da Lama ao Caos e passei a esperar o lançamento do próximo.

Afrociberdelia (título que remete à África, à cibernética e ao

${ }^{2}$ TELES, José. Do frevo ao mangue beat. São Paulo: Editora 34, 2000, p. 229.

${ }^{3}$ SHARP, Daniel Benson. A Satellite Dish in the Shantytown Swamps: Musica Hybridity in the 'New Scene' of Recife, Pernambuco, Brazil. Tese de mestrado. Universidade do Texas, 2001, pp. $42-43$.

${ }^{4}$ GALINSKY, Philip. Maracatu Atomico: Tradition, Modernity, and Postmodernity in the Mangue Movement of Recife, Brazil. Nova York e Londres: Routledge, 2002, p. 2. 
psicodelismo) apareceu em 1996. Muito mais bem produzido que o anterior, o álbum era um tour de force que comprovava a total maturidade da banda. Nascido naquele ano, meu filho Alexandre faria da versão funk hop de Chico Science para o clássico "Maracatu Atômico", do ícone contracultural Jorge Mautner, uma de suas canções favoritas. Em 1997, o manguebeat já acumulara uma força não vista num movimento musical brasileiro desde a rebelião tropicalista do final dos anos sessenta. Village Voice, Spin, New York Times e outros veículos da mídia mundial cobriam os rapazes do mangue enquanto eles planejavam sua terceira turnê europeia. No inverno gelado de 1997, lecionando na Universidade de Illinois, eu esperava poder vê-los de novo, se não em Nova York, pelo menos no meio do ano seguinte, no Brasil.

No dia dois de fevereiro, dia de Iemanjá, dia de festa no mar, domingo de carnaval, Science decidiu pela enésima vez ir dirigindo de Recife até a vizinha Olinda. Iria no carro compacto de sua irmã, por receio de não conseguir estacionar seu Landau 1979 nas ruas atulhadas do carnaval de Olinda. Não chegou e foi encontrado morto no carro, batido contra um poste. Aos 30 anos de idade, desaparecia a personalidade mais inovadora da música brasileira dos anos noventa. Pela primeira vez na história do carnaval do Recife, as principais nações do maracatu desfilaram em silêncio pela cidade, acompanhadas por uma multidão estarrecida. No mesmo dia dois de fevereiro, sete anos antes, Gilberto Gil, a lenda musical cujo destino se unira ao de Science, também havia perdido seu filho mais velho num acidente de carro. Em minha raiva, eu pensava menos em Science e mais em meu filho, Alexandre, e em todos os garotos que jamais veriam os espetáculos impressionantes daquele meu ídolo musical. A Nação Zumbi, seus contemporâneos do Mundo Livre S/A e dezenas de outras bandas pernambucanas que surgiram desde aquela época conduziram o bastão brilhantemente $^{5}$, mas a visionária arte poética, rítmica e performática de Chico Science continua sendo a medida de como o manguebeat se transformou na mais fértil renovação da música brasileira popular das últimas décadas.

Com a primeira grande crise de público e legitimidade da MPB, durante o período da redemocratização (1979-1985), o Brasil testemunhou o surgimento de um fosso crescente entre a música nacional e a música jovem. A maioria dos jovens ouvia bandas de rock anglo-americanas, enquanto grande parte da música nacional produzida pelos nomes canônicos da MPB não era amplamente consumida pela juventude que, não sem razão, começou a associar as estrelas pop nacionais com o status quo, especialmente com a notável indústria do entretenimento desenvolvida no Brasil durante a ditadura. A partir de meados do anos 90, supera-se paulatinamente esse fosso entre música jovem e música nacional que caracterizou os 80. Chico Science, seus

\footnotetext{
${ }^{5}$ Jorge passou a ser o guitarrista da Nação Zumbi e assumiu os vocais e as letras em 1997. Depois da morte de Chico Science, Jorge du Peixe, Lúcio Maia, Bola 8 e companhia demoraram menos de dois anos para reocupar seu lugar no topo das bandas pop brasileiras. Ao longo da trajetória de cinco álbuns lançados sem Science, CSNZ (1997, um CD duplo de homenagem com artistas convidados), Radio S.A.M.B.A. (1998), Nação Zumbi (2002), Futura (2005) e Fome de tudo (2007), a Nação Zumbi foi se movendo na direção do rock pesado, mas manteve vivo o diálogo entre gêneros afro-atlânticos, do maracatu ao hip hop. $\mathrm{O}$ uso dos tambores do maracatu continua sendo uma marca registrada.
} 
colaboradores e seguidores foram os agentes chave desse processo, ao estabelecer uma conversa entre gêneros regionais nunca antes elevados ao status de música nacional e gêneros jovens internacionais, em grande parte afro-atlânticos, nunca antes elevados ao panteão do rock/pop global. Os encontros entre essas duas vastas tradições constitui uma das grandes originalidades do manguebeat. Melhor descrito como uma sucessão de cenas que propriamente como um movimento, o manguebeat se confunde com a história do renascimento do Recife como polo musical: "o Mangue construiu uma política de diferença cultural para a cidade [e] o Recife se viu repentinamente inserido num contexto pós-moderno" ${ }^{\circ}$. Metrópole multicultural construída sobre um pântano quente numa região com altos índices de pobreza--mas frequentemente descrita como "Veneza brasileira", pelos seus lindos estuários e pontes--, Recife viu sua reputação bater recorde negativo no começo dos anos 90: o "Population Crisis Committee", instituto de pesquisa de Washington D.C., classificava a cidade como uma das cinco piores áreas urbanas do planeta, ao lado de Lagos, Dacca, Kanpur e Kinshasa. O ranking deu origem à expressão "quarta pior cidade do mundo", depois ironicamente apropriada pela música manguebeat. Em meados dos anos noventa, a revolução da informação (email, Internet, fax, celulares) começava a globalizar as áreas urbanas do Nordeste brasileiro de maneiras que o Sudeste, mais rico, não percebia de imediato. A circulação crescente de informação permitiu contatos entre jovens da classe média baixa da periferia, como Chico Science, a classe média universitária, de onde vieram Fred 04, líder do Mundo Livre S/A, Renato L e outros, e os músicos negros dos mocambos, de onde sairia grande parte dos percussionistas do manguebeat.

Do frevo ao manguebeat, de José Teles, referência jornalística e testemunhal definitiva, relata a história do encontro emblemático para os mangueboys: aquele que juntou 1) o trabalho que realizavam com o maracatu e o samba reggae de inspiração baiana os percussionistas afro-brasileiros das comunidades de Peixinhos e Chão de Estrelas, 2) as experiências de Chico Science com gêneros musicais afro-americanos como funk e hip-hop e 3) a trajetória de Fred 04, Renato L e outros universitários na cultura jornalística e musical, especialmente punk e pós-punk. Desde a década de 70, o carnaval da Bahia passava por uma reafricanização, com o surgimento dos blocos afro e do samba-reggae ${ }^{7}$. Esses processos tiveram impacto na cena pernambucana, e o grupo de samba-reggae Lamento Negro, parte do núcleo cultural negro Daruê Malungo, da região do Chão de Estrelas, tornou-se uma verdadeira escola para os percussionistas do manguebeat. Gilmar Bola 8, Toca Ogan e Gira, todos dessa região, passaram a compor a Nação Zumbi ${ }^{8}$. A relação com a cultura negra internacional esteve no coração da cena manguebeat desde o começo:

\footnotetext{
${ }^{6}$ PRYSTHON, Angela. Um conto de três cidades: música e sensibilidades culturais urbanas. Ecompós: Revista da Associação Nacional dos Programas de Pós-Graduação em Comunicação, p. 8, 11.1.2008. (Acesso em 16 de março de 2011) http://www.compos.org.br/seer/index.php/ecompos/article/view/273/254

${ }^{7}$ Ver RISÉRIO. Carnaval Ijexá, para o mais completo estudo do processo que veio a ser conhecido como a "reafricanização" do carnaval baiano.
}

${ }^{8}$ TELES, José, op. cit., p. 269. 
"Antes mesmo que Chico aparecesse, André e eu já usávamos cabelo black power. Era uma grande mistura: rap, soul e afoxé. Em casa, sempre comprávamos discos de soul e de reggae". Chico Science, particularmente, cresceu alimentado por doses generosas de James Brown, Curtis Mayfield, Funkadelic e os primeiros artistas do hip hop ${ }^{10}$. No começo da década de 80, na medida em que o fenômeno da dança break aparecia no Recife, "Chico e seu inseparável amigo Jorge du Peixe se juntaram à Legião Hip Hop, um dos maiores grupos de dança break das ruas de Recife"11.

Teles aponta 1987 como o momento chave na emergência da cena que explodiria nacionalmente de seis a sete anos depois. Acabavam de acontecer mudanças no tradicional Jornal do Comércio, permitindo algum espaço na mídia. Naquele momento, o Mundo Livre S/A ainda não convencia suas plateias de que sua "síntese de Johnny Rotten, Jorge Ben e Bezerra da Silva" merecia ser ouvida. Com algumas letras inspiradas em 1984, de George Orwell, Fred 04 "deixou a raiva punk amadurecer e mesclar-se com um cinismo calculado". Serviço Sujo, sua banda anterior, deu lugar ao Mundo Livre S/A, "um nome claramente inspirado em Malcolm MacLaren, ridicularizando Reagan e sua retomada da Guerra Fria, assim como o funcionamento da indústria fonográfica"12. No começo, o Mundo Livre S/A era vaiado pela ousadia de mesclar rock com tamborim e cavaquinho. Suas tentativas de criar um "samba psicodélico" eram rotineiramente ridicularizadas no Recife, mas já continham alguns ingredientes da revolução manguebeat, como a produção de um som que dinamitava as fronteiras entre o rock e a MPB.

$\mathrm{Na}$ primeira edição do Recife Rock Show, em 1993, 57 bandas se inscreveram e veículos importantes da mídia nacional, como a Biž já falavam dos mangueboys. Ao contrário de outros festivais de rock, o RRS apresentou performances de músicos "tradicionais", como Lia de Itamaracá e Dona Selma do Coco. No começo da década de noventa, os princípios básicos da estética manguebeat já tinham sido formulados por seus "intelectuais orgânicos"--além de Science e Fred 04, outros nomes importantes foram DJ Mabuse, o escritor e enfant terrible Xico Sá e os jornalistas Renato Lins e José Teles. Essa estética seria mais tarde formulada no manifesto "Caranguejos com Cérebros", publicado no encarte do álbum Da Lama ao Caos (1994), de CSNZ. A iconografia dos mangueboys substituía as referências à cana-de-açúcar como símbolo da cultura regional pelos caranguejos urbanos ${ }^{13}$. Tratava-se de caranguejos com "cérebros", "antenas fincadas na lama", para captar as correntes globais de informação. Como mostra Herom Vargas, o manguebeat cultivou um hibridismo que fazia a crítica mais pertinente do regionalismo / nacionalismo musical daquela que fora até então a grande baliza na música

\footnotetext{
${ }^{9}$ MAIA apud TELES, José, op. cit., p. 222.

${ }^{10}$ GALINSKY, Philip, op. cit., p. 31.

${ }^{11}$ Idem.

12 ZERO 04 apud GALINSKI, Philip, op.cit., p. 38.

${ }^{13}$ LEÃO DO Ó, Ana Carolina. A maravilha mutante: batuque, sampler e pop no Recife dos anos 90. Tese de mestrado. UFPE, 2002, p. 66.
} 
pernambucana popular, o movimento armorial de Ariano Suassuna ${ }^{14}$. Enquanto a globalização intensificava as contradições sociais de megalópoles como o Recife, ela também permitia que um crescente número de jovens marginalizados adquirissem os meios para representar essa crise e intervir nela através da música, de formas até então inéditas. Em 1994, quando CSNZ e Mundo Livre S/A conquistaram visibilidade para além das fronteiras de Recife e Olinda, a música pernambucana já não atraía atenção nacional havia mais de 15 anos, desde a época do ícone contra-cultural Alceu Valença ou do trovador roqueiro e paraibano adotado Zé Ramalho. Se, a princípios da década de 90, era possível que o ídolo Alceu Valença dissesse que "Pernambuco está velho... e morrendo de mofo" ${ }^{15}$, cinco anos depois era público e notório entre ouvintes de música popular em todo o país que a música jovem mais inovadora do Brasil estava sendo produzida precisamente em Pernambuco. Entre a entrevista de Alceu Valença, em 03/1992, e o estabelecimento deste relativo consenso, aproximadamente em 1996-97, o manguebeat realizou nada menos que uma pequena revolução no cânone da música popular brasileira, capitaneada por quatro discos: Da Lama ao Caos (1994) e Afrociberdelia (1996), de CSNZ, e Samba Esquema Noise (1994) e Guentando a Ôia (1996), do Mundo Livre S/A. Mas a cena também inclui uma vasta produção de artistas que têm muito pouco a ver uns com os outros em termos estritamente musicais. Associam-se à cena bandas que fazem um uso criativo do acordeão, como o Mestre Ambrósio, bandas de rock que aprenderam as lições iconoclastas do manguebeat, como Querosene Jacaré, músicos que experimentaram os recursos da música eletrônica, como Otto (ex-baterista do Mundo Livre S/A de carreira solo estelar), pastiches de gêneros nacionais e estrangeiros do Mombojó, releituras punk do baião feitas pelo Cascabulho (grupo depois desfeito, para que o líder Silvério Pessoa seguisse carreira solo) e uma legião de músicos que aproveitaram essa intensa liberdade de experimentar e combinar influências internacionais com as formas regionais.

Ao lado de outras formas musicais contemporâneas como o hip-hop, o manguebeat restaurou a possibilidade de fazer da música popular uma esfera de ação política, relativamente atrofiada desde a MPB dos anos setenta ${ }^{16}$. A cena pernambucana também atualizou a Tropicália, ao oferecer novamente outro grande gesto inaugural, com manifestos e afins ${ }^{17}$. Talvez pela primeira vez desde os primórdios do samba, um movimento musical unia 1) percussionistas afro-brasileiros das classes populares, 2) a juventude mestiça, de classe média baixa e 3) jovens intelectuais saídos das universidades. O manguebeat também mobilizou músicos em torno de causas como a inclusão digital e a revisão das leis do direito autoral. Mais do que apenas uma renovação do cânone musical,

\footnotetext{
${ }^{14}$ Cf. VARGAS, Herom. Hibridismos musicais de Chico Science e Nação Zumbi. Cotia, SP: Ateliê, 2007.

${ }^{15}$ Cf. TELES, 2000.

${ }^{16}$ Uma versão anterior deste ensaio defendia, exageradamente, a primazia e a originalidade do manguebeat na restauração de manifestações políticas coerentes e coletivas na música popular. Uma excelente pergunta de Jason Stanyek me fez ver que essa afirmação precisava ser relativizada.

17 Para dois estudos definitivos da Tropicália como grande gesto inaugural, ver DUNN. Brutality Garden. FAVARETTO. Tropicália: Alegoria alegria.
} 
foi uma transformação das relações entre música e política no país. Como no caso da Tropicália, o que caracteriza o manguebeat não é uma batida ou ritmo peculiar, mas uma certa atitude com relação às misturas musicais. $O$ manguebeat se constituiu no Recife, criando um som distinto, baseado em combinações que não seriam possíveis em nenhum outro lugar do mundo (maracatu e hip hop, por exemplo), mas ao mesmo tempo também questionando o que se entendia como "música nacional" durante o reinado da MPB. Não que o manguebeat tenha tornado a MPB irrelevante como categoria musical, ou mesmo que tivesse sido "contra" a MPB. Mas a mistura sem precedentes do internacional com o que era entendido como regional, sem passar pela mediação da música canonizada como nacional no Sudeste, mudou os paradigmas de canonização na canção popular. O manguebeat é o mais próximo que a música brasileira popular recente chegou de um grande gesto inaugural ou de um momento de ruptura com a tradição. Seu movimento inclui tanto a revisão e a recuperação da tradição como a ruptura, esta última encarnada na crítica ao pensamento dominante sobre música pernambucana e nordestina emblematizado na perspectiva nacional-preservadora de um populista como Ariano Suassuna. O manguebeat se apresentou como música jovem, mas não tinha as restrições dos roqueiros da década de 80 ao cancioneiro regional. A cena foi local em suas múltiplas referências a Pernambuco, mas não rejeitava a música estrangeira como constumava ser o caso em boa parte dos músicos brasileiros associados a uma localidade ou região. O legado do manguebeat abre caminho para um uso consciente da liberdade de atravessar, ou inclusive dinamitar, fronteiras que antes eram concebidas como estáveis e intransponíveis.

Definido como "não apenas as gravações de algumas novas bandas [mas]...como uma coalizão de músicos que desenvolviam...novas ideias para a música pop," ${ }^{18}$ o manguebeat dialogou intensamente com a música nordestina, especialmente a pernambucana, mas ao contrário de gêneros regionais anteriores, ele estabeleceu uma conversa explícita com as influências estrangeiras. Por outro lado, o manguebeat fez vasto uso de recursos da música jovem internacional (reggae, hip hop, funk, metal) mas, ao contrário dos primeiros praticantes brasileiros desses gêneros no Brasil, ele também manteve uma forte relação com tradições locais. Alguns dos músicos associados com a cena manguebeat demonstraram compromisso com questões políticas como inclusão digital e democratização do acesso à mídia, mas não se via, na sua prática, aquela submissão da música à política tão típica da militância da década de sessenta. O manguebeat foi, portanto, uma ave rara, que realizou combinações nunca antes tentadas: enraizado localmente, mas ferozmente global; radical e demolidor mas claramente aberto à tradição; visivelmente político mas consciente dos limites da política na música.

Os gêneros musicais afro-diaspóricos foram os mediadores chave que permitiram ao manguebeat formular uma resposta musical criativa para o encontro entre a revolução da informação e a crise do nacionalismo na música popular brasileira. O repertório pop global havia inspirado os tropicalistas no final dos anos 60 e os ícones do punk e pós-punk anglo-americanos foram

${ }^{18}$ SHARP, Daniel Benson, op. cit., pp. 37-38. 
decisivos para a geração de roqueiros que se formou na década de 80. Mas com Chico Science o repertório da música negra internacional começa a dialogar com as músicas jovens brasileiras de forma consistente. $\mathrm{O}$ manguebeat representa também, então, a introdução definitiva da referência do Atlântico Negro $^{19}$ na música jovem brasileira. A grande originalidade da leitura de Science é que ele percebe que aí se encontrava o vínculo que permitia um diálogo entre formas naquele momento consideradas quase folclóricas, como o maracatu, e gêneros da música diaspórica jovem, como o hip hop.

Os álbuns Da Lama ao Caos e Afrociberdelia, de CSNZ, preferiram a mescla de gêneros internacionais afro-atlânticos e tradições nordestinas brasileiras ao rock internacional mainstream (Led Zeppelin, Sabbath, Pink Floyd, Deep Purple) que já era bem influente no Brasil. Tampouco foram muito centrais as formas já nacionalizadas de música brasileira, ou seja, formas já associadas com um cânone nacional, como a bossa nova, a MPB ou o samba. As influências de Chico Science incluem artistas cujo trabalho dialogava com o samba ou com a MPB (um exemplo importante é o Fellini, banda paulista de vanguarda dos anos oitenta, pioneira no uso caseiro e criativo de gravadores de oito canais) mas, apesar da visão de cultura de Chico Science possuir traços de diálogo com o legado tropicalista, os principais ingredientes do seu trabalho foram gêneros internacionais marginais ao panteão do pop rock (especialmente gêneros afro-atlânticos) e uma vasta gama de tradições musicais pernambucanas e nordestinas. A "linha evolutiva" da música popular brasileira, aquela entendida como o cânone nacional, não cumpre papel muito relevante na estética do manguebeat. Algo a crítica já disse sobre a dívida do manguebeat com o Tropicalismo, mas pouco foi dito sobre esse dado visível, óbvio mesmo da arte dos mangueboys: sua constelação representa uma alternativa à hipótese da "linha evolutiva", com a qual o principal intelectual orgânico do Tropicalismo, Caetano Veloso, recodificava a ruptura como, no fundo, uma restauração.

Ao longo da obra dos mangueboys, são muitos os exemplos desse encontro de formas musicais tangenciais, laterais aos cânones nacional e internacional. Os cerimoniosos e solenes versos de abertura da primeira faixa de Afrociberdelia, "Mateus Enter" (que conclui com o epigramático dístico "Pernambuco embaixo dos pés / e minha mente na imensidão"), são recitados sobre uma guitarra em power chord, no estilo heavy metal, enquanto a percussão embarca num ritmo de maracatu. Na nona faixa de Da lama ao caos, "Salustiano Song", uma levada de tambores de maracatu dialoga com um padrão rítmico de música de candomblé. Sobre esse diálogo polirrítmico, ouvese uma melodia soporífera no sintetizador, num dos muitos tributos de Chico Science à música eletrônica. Em "Risoflora", oitava faixa do mesmo Da lama ao caos, as guitarras distorcidas se sobrepõem ao crescendo dos tambores que fraseiam o maracatu. A terceira faixa do mesmo disco, "Rios, pontes e overdrives" (a gravação original desse verdadeiro clássico do manguebeat),

\footnotetext{
${ }^{19}$ O termo vem da obra de Gilroy, The Black Atlantic, que demonstra a impossibilidade de se pensar a constituição da modernidade e de todos os seus componentes - a secularização, o racionalismo etc.-- sem referência ao processo de escravização das populações africanas e ao tráfico negreiro no Atlântico.
} 
explora inúmeras variações de gêneros nordestinos, como o maracatu e o baião, na parte $\mathrm{A}$, assim como o parentesco entre o hip hop e o embolada, duas artes verbais baseadas no poder rítmico da língua, na parte B. A quarta faixa, a contagiante "A Praieira", tornou-se canônica no repertório do manguebeat, tanto pela sua sobreposição de um groove rock-funk sobre um ritmo de ciranda como por sua notável letra, que descreve acidamente as dores e esperanças do Recife: "a cidade não pára / a cidade só cresce / o de cima sobe / o de baixo desce".

"Cidadão do Mundo", segunda faixa de Afrociberdelia, se constrói sobre uma conversa entre a seção rítmica e a linha vocal: em A/A', a seção rítmica estabelece um groove funk enquanto os vocais de Science respondem com uma melodia cerimonial do maracatu submetida a distorção. Em B/B', a linha melódica do maracatu continua nos vocais, mas desta vez sobre um groove também de maracatu na seção rítmica. Quando chegamos à parte $C$, a seção rítmica já passou a um groove funk (levada agora no berimbau) e a linha vocal decolou num rap frenético que também alude, simultaneamente, à embolada ${ }^{20}$. Nos vocais da parte C, já não é possível distinguir se Science está embolando ou rapeando: explora-se o parentesco entre duas artes verbais afro-atlânticas. A aproximação entre gêneros díspares na música de Chico Science, no entanto, nunca toma a forma de uma fusão. Ela oferece uma sequência de justaposições que se tornam cada vez mais complexas, estabelecendo contrastes e interseções. Não se trata, em outras palavras, de uma convergência na direção de uma síntese, mas uma prática modulada de interrupções.

CSNZ combinava as células rítmicas mais comuns do maracatu, o padrão $16^{\mathrm{a}}-8^{\mathrm{a}}-16^{\mathrm{a}}$ nota (acentuado na segunda), com um groove funk vindo do outro lado da seção rítmica. Enquanto a percussão e o baixo tocavam funk ou maracatu, Science frequentemente não cantava no estilo respectivo. A linha vocal fazia outra coisa, estabelecia um padrão rítmico próprio. Produzia-se assim um efeito de desnaturalização e estranhamento nos ouvintes acostumados a um casamento mais "harmonioso" e convencional entre vocais e música. Além dessa conversa rítmica, as cordas frequentemente iam de um solo distorcido de heavy metal tocado com a ajuda de pedais wah wah até um samba-soul dançante e eletrificado no estilo de Jorge Ben Jor. A música é pontuada por vários usos do sampler, marcando interrupções abruptas. Os vários tempos da percussão do maracatu tornaram-se parte integral dos shows de CSNZ, mesmo na medida em que suas outras influências foram se tornando mais diversificadas.

A letra de "Cidadão do Mundo" oferece um retrato duro da violência repressora sobre um escravo fugitivo: "A estrovenga girou / Passou perto do meu pescoço". O sujeito reage ao susto juntando sua "nação": "Jurei, jurei / Vou pegar aquele capitão / Vou juntar a minha nação / Na terra do maracatu". A cerimônia da coroação do Rei do Congo no maracatu é vista como um reflexo do surgimento dessa nova nação, a Nação Zumbi ${ }^{21}$. Quando o sujeito jura que vai "pegar aquele capitão", nota-se a alusão aos "capitães do mato",

\footnotetext{
${ }^{20}$ GALINSKY, Philip, op. cit, pp. 43-45.

${ }^{21}$ Tanto o nome da banda, quanto a letra de "Cidadão do Mundo", fazem referência, naturalmente, a Zumbi dos Palmares.
} 
encarregados de perseguir escravos ${ }^{22}$. O tom cerimonial é quebrado pelo verso "Só tem caranguejo esperto / Saindo desse manguezal", que une o humor à característica visão crítica de Science sobre as misérias humanas do mangue. A estrofe final, em ritmo de rap, descreve duas rápidas cenas de pequenos roubos, contadas do ponto de vista de um narrador que simpatiza com os ladrões ou talvez seja um deles. Essa identificação com o transgressor de uma lei vivida e percebida como injusta e mal aplicada era uma das características da cultura hip hop que atraía Chico. Essas cenas de pequenos roubos, conflitos e encontros de gangues para uma guerra indefinida mas iminente são comuns na música de Science. A descrição dessas cenas nas letras é frequentemente acompanhada de um aumento da tensão musical, através de operações sobre o volume, o andamento e o ritmo. Como demonstrou Herom Vargas, "a violência torna-se um ingrediente importante e está não apenas na aparência mais imediata das letras, mas também nas formas de vestimenta no gestual"23.

Além da atitude, vestuário e ideias, Science também pega emprestado as batidas desses gêneros regionais e internacionais. É principalmente nos ritmos que Science viu como o diálogo entre gêneros musicais poderia dar-lhe uma nova metáfora para a tradução e o contato cultural. A criação de canais de comunicação entre gêneros afro-atlânticos (ska, reggae, hip hop, funk, raggamuffin) e gêneros brasileiros que nunca atingiram o status de música nacional e continuaram a ser considerados regionais (coco, embolada, maracatu, ciranda) mudou significativamente o cânone do que contava como música brasileira. Não apenas gerou um considerável e rico corpus musical, mas também demonstrou a um largo segmento de praticantes de música jovem que culturas musicais antes vistas como antagônicas e mutualmente excludentes podiam dialogar entre si. $\mathrm{O}$ mérito de Science foi ter visto o potencial rítmico, melódico, performático e político desses encontros. Antes de mais nada, o manguebeat foi um formidável questionamento da divisão social do trabalho auditivo no Brasil.

Se o samba é uma parte relativamente pequena do mosaico criado por Chico Science e pela Nação Zumbi, o mesmo não pode ser dito sobre o Mundo Livre S/A, cujo trabalho promove uma releitura das diferentes vertentes do gênero. O próprio título do primeiro disco da banda, Samba Esquema Noise, traz alusão clara a Jorge Ben Jor, cujo Samba Esquema Novo, de 1963, foi momento chave em sua eletrificação do samba. Na faixa dois, "A Bola do Jogo", a introdução na guitarra deixa bem nítida a marca do Ben Jor do primeiro período. O famoso cavaquinho de Fred 04 ganha destaque na terceira faixa, "Livre Iniciativa", canção que alterna guitarras distorcidas em estilo heavy metal com o samba tocado no cavaquinho. A versão do Mundo Livre de "Rios, Pontes e Overdrives", verdadeiro clássico do manguebeat, é um interessante contraponto à versão canônica e mais conhecida de CSNZ. Enquanto Science privilegia um som mais upbeat e dançante, a versão do Mundo Livre desacelera o andamento, conferindo-lhe uma qualidade meditativa. Em oposição aos tambores em CSNZ, a versão do Mundo Livre

\footnotetext{
22 Agradeço a Alexandre Silva por chamar minha atenção às referências aos capitães do mato nesta canção.

${ }^{23}$ VARGAS, Herom, op. cit., p. 133.
} 
justapõe batidas suingadas de samba na guitarra, acelerando até um rock pesado, para depois diminuir a velocidade e quebrar a sintaxe melódica mais uma vez, passando a um reggae. O Mundo Livre S/A pode ser definido como uma central psicodélica de transformação de materiais pop. Nessa mistura, tanto o samba quanto o rock new wave tiveram papéis fundamentais. Ao longo dos anos 90, o Mundo Livre S/A participou de eventos como o Fórum Social Mundial de Porto Alegre, num ativismo que deixou de ser exclusivamente musical para tornar-se político. Mais diretamente envolvido em política que seus amigos na Nação Zumbi, Fred 04 manteve contatos internacionais que vão de Noam Chomsky ao Comandante Marcos e fez aparições em vários momentos no movimento anti-globalização.

Causando um embaralhamento na música brasileira ao colocar em contato gêneros antes considerados regionais com vastas gamas de músicas internacionais de origem afro-atlântica, o manguebeat superou a codificação do filtro sancionado do cânone nacional. Substituiu a velha iconografia canavieira do Nordeste pelos antenados caranguejos urbanos, imagem de uma cidadania cultural ao mesmo tempo local e global. Inspirou uma verdadeira revolução faça-você-mesmo e deixou um legado na música popular brasileira que continua aberto a leituras, longe de se esgotarem. Acima de tudo, o manguebeat superou um fosso entre a música jovem e a música nacional que havia caracterizado um momento anterior na cultura brasileira, tornando mais permeável a relação entre o que se canoniza como nacional e o que se vivencia musicalmente como jovem no Brasil.

\section{Referências bibliográficas}

DUNN, Christopher. Brutality Garden: Tropicália and the Emergence of a Brazilian Counterculture. Chapel Hill: U of North Carolina P, 2001.

FAVARETTO, Celso. Tropicália: Alegoria alegria. São Paulo: Ateliê, 1979.

GALINSKY, Philip. Maracatu Atômico: Tradition, Modernity, and Postmodernity in the Mangue Movement of Recife, Brazil. Nova York e Londres: Routledge, 2002.

GILROY, Paul. The Black Atlantic: Modernity and Double Consciousness. Cambridge: Harvard UP, 1993.

LEÃO DO Ó, Ana Carolina. A maravilha mutante: batuque, sampler e pop no Recife dos anos 90. Tese de mestrado. UFPE, 2002.

PRYSTHON, Angela. Um conto de três cidades: música e sensibilidades culturais urbanas. Ecompós: Revista da Associação Nacional dos Programas de PósGraduação em Comunicação, pp. 1-13, 11.1.2008. (Acesso em 16 de março de 2011) http://www.compos.org.br/seer/index.php/e-compos/article/view/273/254 
RISÉRIO, Antonio. Carnaval Ijexá. Salvador: Corrupio, 1981.

SHARP, Daniel Benson. A Satellite Dish in the Shantytown Swamps: Musica Hybridity in the 'New Scene' of Recife, Pernambuco, Brazil. Tese de mestrado. Universidade do Texas, 2001.

TELES, José. Do frevo ao mangue beat. São Paulo: Editora 34, 2000.

VARGAS, Herom. Hibridismos musicais de Chico Science e Nação Zumbi. Cotia: Ateliê, 2007. 